\title{
Beta-cell dysfunction and glucose intolerance: results from the San Antonio metabolism (SAM) study
}

\author{
A. Gastaldelli1 ${ }^{1,3}$, E. Ferrannini ${ }^{1,2,3}$, Y. Miyazaki ${ }^{3}$, M. Matsuda ${ }^{3}$, R. A. DeFronzo ${ }^{3}$ \\ ${ }^{1}$ Metabolism Unit, C.N.R. Institute of Clinical Physiology, Pisa, Italy \\ ${ }^{2}$ Department of Internal Medicine, University of Pisa School of Medicine, Pisa, Italy \\ ${ }^{3}$ Diabetes Division, University of Texas Health Science Center, San Antonio, Tex., USA
}

\section{Abstract}

Aims/hypothesis. Both insulin resistance and beta-cell dysfunction play a role in the transition from normal glucose tolerance (NGT) to Type 2 diabetes (T2DM) through impaired glucose tolerance (IGT). The aim of the study was to define the level of glycaemia at which beta-cell dysfunction becomes evident in the context of existing insulin resistance.

Methods. Insulin response (OGTT) and insulin sensitivity (euglycaemic insulin clamp) were evaluated in 388 subjects in the San Antonio Metabolism (SAM) study (138 NGT, 49 IGT and 201 T2DM). In all subjects the insulin secretion/insulin resistance index $(\Delta \mathrm{I} / \Delta \mathrm{G} \div \mathrm{IR})$ was calculated as the ratio of the increment in plasma insulin to the increment in plasma glucose during the OGTT divided by insulin resistance, as measured during the clamp.

Results. In lean NGTs with a 2-h plasma glucose concentration (2-h PG) between 5.6 and 6.6 and between
6.7 and $7.7 \mathrm{mmol} / \mathrm{l}$, there was a progressive decline in $\Delta \mathrm{I} / \Delta \mathrm{G} \div \mathrm{IR}$ compared with NGTs with a 2 -h PG less than $5.6 \mathrm{mmol} / \mathrm{l}$. There was a further decline in $\Delta \mathrm{I} / \Delta \mathrm{G} \div \mathrm{IR}$ in IGTs with a $2-\mathrm{h}$ PG between 7.8 and 9.3 and between 9.4 and $11.0 \mathrm{mmol} / \mathrm{l}$, and in Type 2 diabetic patients with a $2-\mathrm{h}$ PG greater than $11.1 \mathrm{mmol} / \mathrm{l}$. Lean and obese subjects showed coincident patterns of relation of $2-\mathrm{h} P G$ to $\Delta \mathrm{I} / \Delta \mathrm{G} \div \mathrm{IR}$.

Conclusion/interpreation. When the plasma insulin response to oral glucose is related to the glycaemic stimulus and severity of insulin resistance, there is a progressive decline in beta-cell function that begins in "normal" glucose tolerant individuals. [Diabetologia (2004) 47:31-39]

Keywords Diabetes - glucose tolerance - OGTT - insulin resistance - insulin secretion - beta-cell function . IGT $\cdot$ NGT
The San Antonio Metabolism (SAM) study was designed to examine the major determinants (insulin secretion and insulin sensitivity) of glucose homeostasis $[1,2]$ in the population of South Texas, which is com-

Published online: 10 December 2003

(C) Springer-Verlag 2003

R. A. DeFronzo MD (-) Diabetes Division, University of Texas Health Science Center, 7703 Floyd Curl Drive MS 7886, San Antonio, Tex., USA

E-mail: albarado@uthscsa.edu

Abbreviations: T2DM, Type 2 diabetes mellitus; FPG, fasting plasma glucose; 2-h PG, 2-h plasma glucose; EGP, endogenous glucose production; Ra, rate of appearance; TGD, total glucose disposal; IR, insulin resistance. prised primarily of Mexican Americans and Caucasians. Like the Pima Indians [3], Mexican Americans are very insulin-resistant and have a high incidence of Type 2 diabetes (T2DM) [4, 5]. The goal of the SAM study was to relate the severity of glucose intolerance to the severity of beta-cell dysfunction and insulin resistance in muscle and the liver. An advantage of the SAM study is that it allows one to compare abnormalities in insulin secretion following the normal route (oral) of glucose administration and insulin sensitivity, as measured directly with the euglycaemic insulin clamp, in the same individual in two major ethnic groups, Mexican Americans and Caucasians.

In the natural history of T2DM, individuals progress from normal glucose tolerance (NGT) to im- 
paired glucose tolerance (IGT) to overt T2DM [1, 2, $3,6,7,8]$. A similar natural history has been shown in the Rhesus monkey [9]. This progression has been demonstrated in populations of diverse ethnic background $[6,7,8,10,11,12]$. In populations with a high prevalence of T2DM, insulin resistance is well established long before the development of any impairment in glucose homeostasis $[1,2,3,5,6,9,10$, $11,12]$. As long as the beta cell is able to secrete sufficient amounts of insulin to offset the severity of insulin resistance, glucose tolerance remains normal $[1$, $2,3,13,14,15,16,17,18]$. This dynamic interaction between insulin secretion and insulin resistance is essential to the maintenance of NGT $[1,3,6,7,9,14$, $15,16,17,18]$ and interruption of this cross-talk between the beta cell and peripheral tissues results in the progressive deterioration of glucose homeostasis $[1,3,14,17,18,19]$. Among individuals with NGT it has been proposed that about $20 \%$ are insulin resistant $[15,20,21,22]$. Using the hyperglycaemic clamp technique, we have shown that these NGT, insulinresistant individuals are able to appropriately augment both first- and second-phase insulin secretion to offset the insulin resistance $[13,15]$; similar results have been reported by others [16, 17, 18, 19]. Individuals with IGT have been shown to have a normal, increased, or impaired early insulin response, although second-phase insulin response generally is increased $[1,3,7,10,12,17,18,23,24,25,26]$. However, the appropriateness of a "normal" or "increased" early/ late-phase insulin response can be evaluated only when viewed in the context of the glucose stimulus to the beta cell [27], the severity of insulin resistance $[15,16,17,18]$, and the impact of glucose potentiating factors, including incretins [28, 29]. At present, such a comprehensive evaluation of beta-cell function has yet to be undertaken. Moreover, the precise level of glycaemia at which beta-cell dysfunction manifests itself remains unknown. It generally is assumed that insulin secretion starts to become impaired in individuals with IGT $[1,3,16,17$, $18,23,24,25,26]$. However, the glucose diagnostic criteria for IGT are somewhat arbitrary and unrelated to physiological abnormalities in insulin secretion and/or insulin resistance [30]. Thus, it is possible that beta-cell dysfunction begins in individuals with $2-\mathrm{h}$ plasma glucose concentrations on the OGTT that are less than $7.8 \mathrm{mmol} / \mathrm{l}$, that is, in individuals with "normal" glucose tolerance.

In this study, we have independently measured both insulin resistance (with the euglycaemic insulin clamp) and the plasma insulin response to oral glucose in individuals whose glucose tolerance ranged from NGT to IGT to overt T2DM. The incremental plasma insulin response was related both to the incremental glucose stimulus presented to the beta cell and to the severity of insulin resistance.

\section{Material and methods}

\section{Subjects}

The study group included 388 subjects non-consecutively recruited at the Clinical Research Center of the University of Texas Health Sciences Center at San Antonio, Texas, where all studies were conducted. A 75-g OGTT was carried out in each subject, who then was classified as having NGT (fasting glucose $<6.1 \mathrm{mmol} / 1$ and 2-h glucose $<7.8 \mathrm{mmol} / \mathrm{l}, n=138$ ) or IGT (fasting glucose $<7.0 \mathrm{mmol} / \mathrm{l}$ and 2 -h glucose between 7.8 and $11.1 \mathrm{mmol} / 1, n=49$ ) or T2DM (fasting glucose $\geq 7.0 \mathrm{mmol} / \mathrm{l}$ or 2-h glucose greater than $11.1 \mathrm{mmol} / \mathrm{l}, n=201$ ) according to the ADA criteria [24]. Of the IGT subjects, seven also had impaired fasting glucose (IFG, i.e., fasting glucose between 6.1 and $7.0 \mathrm{mmol} / \mathrm{l}$ ). Of the study population, $70 \%$ of NGT, $76 \%$ of IGT and $76 \%$ of T2DM were of Mexican-American ethnicity, while the remainder were of Caucasian descent ( $p=\mathrm{NS}$ between groups). This ethnic distribution reflects the population in the San Antonio area. History of diabetes in first-degree relatives (FHD) was obtained from all subjects and was positive in $51 \%$ of NGT, $73 \%$ of IGT and $62 \%$ of T2DM $(p<0.01$ IGT vs NGT, $p<0.001$ T2DM vs NGT).

All study subjects had normal liver, cardio-pulmonary, and kidney function as determined by medical history, physical examination, screened blood tests, EGK, and urinalysis. No NGT or IGT subject was taking any medication know to affect glucose tolerance. T2DM subjects taking sulphonylureas $(25 \%)$ had their oral hypoglycaemic agent discontinued 3 days prior the study. No T2DM subject ever had received treatment with metformin, a thiazolidinedione, or insulin. None of the subjects participated in any regular physical activity program. Body weight was stable for at least 3 months prior to study in all subjects. By defining obesity as a BMI greater than $30 \mathrm{~kg} \cdot \mathrm{m}^{-2}$, or a BMI greater than $27 \mathrm{~kg} \cdot \mathrm{m}^{-2}$ with body fat greater than 35\% [31], 49 NGT, 30 IGT and 139 T2DM subjects were obese and 89 NGT, 19 IGT and 69 T2DM subjects were non-obese. The study protocol was approved by the Institutional Review Board of the University of Texas Health Science Center at San Antonio, and informed written consent was obtained from each subject prior to their participation.

Experimental protocol

Anthropometric measurements. The waist-to-hip circumference ratio (WHR) was determined by measuring the waist circumference at the narrowest part of the torso and the hip circumference in a horizontal plane at the level of the maximal extension of the buttocks. Fat-free mass (FFM) was measured using tritiated water [32].

Metabolic measurements. All metabolic tests were carried out at the Clinical Research Center in the morning (from 7:00 to 8:00 am) after a 10- to 12-h overnight fast. For the OGTT, blood samples were collected at $-30,-15,0,30,60,90$, and $120 \mathrm{~min}$ for the measurement of plasma glucose, free fatty acids (FFA), C-peptide and insulin concentrations. Prior to the start of the euglycaemic hyperinsulinaemic clamp (120 min or $180 \mathrm{~min}$ in diabetic subjects), all subjects received a prime (740 kBq)-continuous $(7.4 \mathrm{kBq} / \mathrm{min})$ infusion of $3-\left[{ }^{3} \mathrm{H}\right]$ glucose (DuPont-NEN, Boston, Mass., USA), which was continued throughout the study. In diabetic subjects the tracer prime was increased in proportion to the increase in fasting plasma glucose as follows: prime $=(\mathrm{FPG} / 5.6) * 740 \mathrm{kBq}$. After the basal tracer equilibration period, subjects received a primed-continu- 
ous insulin infusion at the rate of $240 \mathrm{pmol} \cdot \mathrm{min}^{-1} \cdot \mathrm{m}^{-2}$ for $120 \mathrm{~min}$. During the last $30 \mathrm{~min}$ of the basal equilibration period, plasma samples were taken at 5- to 10-min intervals for the determination of plasma glucose and insulin concentrations and tritiated glucose specific activity. During insulin infusion, the plasma glucose concentration was measured every $5 \mathrm{~min}$, and a variable glucose infusion was adjusted, based on the negative feedback principle, to maintain the plasma glucose level between 5.0 and $5.6 \mathrm{mmol} / \mathrm{l}$ with a coefficient of variation of less than 5\% [33]. Plasma samples were collected every $15 \mathrm{~min}$ from 0 to $90 \mathrm{~min}$ and every 5 to $10 \mathrm{~min}$ from 90 to $120 \mathrm{~min}$ for the determination of plasma glucose and insulin concentrations and tritiated glucose specific activity [34].

Analytical techniques. Plasma glucose was measured by the glucose oxidase reaction (Beckman Glucose Analyzer, Fullerton, Calif., USA). Plasma insulin and C-peptide concentrations were measured by radioimmunoassay using specific kits (DPC, Los Angeles, Calif., USA) and serum FFA were measured spectrophotometrically (Wako, Neuss, Germany). Plasma 3-[3 H]glucose levels were measured in Somogyi precipitates as previously described [34].

Data analysis. Glucose and insulin areas under the OGTT curve (AUC) were calculated using the trapezoidal rule. During the insulin clamp, total rates of glucose appearance (Ra) and disappearance (TGD) were calculated using Steele's equation [35]. Values for $\mathrm{Ra}$ and TGD represent those during the last $40 \mathrm{~min}$ of the clamp. Peripheral insulin resistance (IR) was calculated as the inverse of TGD during the last $40 \mathrm{~min}$ of the clamp, normalized by the steady state plasma insulin concentration $(1 \div[\mathrm{TGD} / \mathrm{I}])$. In the basal post-absorptive state, endogenous glucose production (EGP) primarily reflects hepatic glucose release. The hepatic insulin resistance index was calculated as the product of EGP and fasting plasma insulin, as validated previously [36]. Over the range of plasma insulin concentrations that are typically seen under basal conditions $(55 \pm 3$ to $75 \pm 4$ to $110 \pm 4 \mathrm{pmol} / \mathrm{l})$, there is a linear relationship between the increase in the plasma insulin level and the decrease in hepatic glucose production $(\mathrm{r}=0.92, p<0.001)$ [34].

Statistical analysis. All data are presented as the means \pm SE. Group values were compared by ANOVA and BonferroniDunn post hoc analysis. Associations between variables were tested with the use of Spearman rank correlations. The contribution of multiple factors to the measured variables was tested by multivariate analysis by using mixed models with both continuous (e.g., age and BMI) and categorical (e.g., sex, familial diabetes, and ethnicity) variables. A $p$ value less than 0.05 was considered statistically significant.

\section{Results}

Clinical characteristics. Subjects were grouped according to their oral glucose tolerance (i.e., NGT, IGT, T2DM) and sub-grouped according to their fasting plasma glucose (FPG) concentration to give approximately equal numbers of subjects in each subgroup (Table 1). There were no differences in sex or ethnic distribution amongst the groups. T2DM subjects, and, to a lesser extent, IGT subjects tended to be slightly older and to have greater BMI, fat mass and central adiposity than NGT individuals. The fasting plasma glucose, FFA, and insulin concentrations were higher in IGT and T2DM groups compared with NGT subjects with a FPG less than $5.0 \mathrm{mmol} / \mathrm{l}$ (Table 2).

Hepatic and peripheral glucose metabolism. During the post-absorptive state, glucose clearance was reduced in IGT and diabetic subjects. The hepatic insulin resistance index was increased in both IGT and diabetic subjects compared to NGT subjects with FPG less than 5.0 and less than $5.3 \mathrm{mmol} / \mathrm{l}$ (Table 2). During the clamp, insulin-mediated total glucose disposal (TGD) was reduced in IGT and diabetic subjects compared to all control groups. TGD was inversely related to both FPG $(\mathrm{r}=0.53, p<0.001)$ and 2 -h plasma glucose concentration during the OGTT (2-h PG) $(r=0.59$, $p<0.001)$. Post-hepatic insulin clearance was reduced in IGT and T2DM subjects compared to NGT subjects with FPG less than $5.0 \mathrm{mmol} / \mathrm{l}$ (Table 2).

Insulin response and fasting plasma glucose. The relationship between the plasma insulin response during the OGTT and FPG displayed the typical inverted

Table 1. Clinical characteristics

\begin{tabular}{|c|c|c|c|c|c|c|c|c|}
\hline & \multicolumn{3}{|l|}{ NGT } & \multirow{2}{*}{$\frac{\mathrm{IGT}}{\mathrm{FPG}<7.0}$} & \multicolumn{4}{|c|}{ Diabetic patients } \\
\hline & $\mathrm{FPG}<5.0$ & $\mathrm{FGP}<5.3$ & $\mathrm{FPG}<6.1$ & & $\mathrm{FPG}<8.0$ & $\mathrm{FPG}<9.7$ & $\mathrm{FPG}<12.2$ & $\mathrm{FPG}>12.2$ \\
\hline $\operatorname{Sex}(F / M)$ & $32 / 14$ & $23 / 24$ & $22 / 23$ & $31 / 18$ & $32 / 18$ & $25 / 25$ & $19 / 31$ & $25 / 26$ \\
\hline Ethnicity (C/MA) & $12 / 34$ & $14 / 33$ & $16 / 29$ & $12 / 37$ & $13 / 37$ & $14 / 36$ & $11 / 39$ & $10 / 40$ \\
\hline FHD $(\%)$ & $22(48 \%)$ & $25(53 \%)$ & $23(51 \%)$ & $36(73 \%)$ & $35(70 \%)$ & $30(60 \%)$ & $30(60 \%)$ & $29(57 \%)$ \\
\hline Fat mass $(\mathrm{kg})$ & $23 \pm 1$ & $26 \pm 1$ & $29 \pm 2 *$ & $31 \pm 1 *$ & $34 \pm 2 *$ & $34 \pm 1 *$ & $33 \pm 2 *$ & $34 \pm 1 *$ \\
\hline Fat-free mass (kg) & $47 \pm 1$ & $50 \pm 1$ & $52 \pm 1 *$ & $51 \pm 1 *$ & $51 \pm 1 *$ & $54 \pm 1 *$ & $55 \pm 1 *$ & $54 \pm 1 *$ \\
\hline Waist (cm) & $87 \pm 4$ & $92 \pm 2$ & $96 \pm 4 *$ & $102 \pm 2 *$ & $107 \pm 2 *$ & $101 \pm 4 *$ & $102 \pm 2 *$ & $102 \pm 2 *$ \\
\hline WHR & $0.84 \pm 0.02$ & $0.90 \pm 0.02 *$ & $0.88 \pm 0.02$ & $0.93 \pm 0.01 *$ & $\quad 0.94 \pm 0.01 *$ & $0.96 \pm 0.01 *$ & $0.95 \pm 0.01 *$ & $\quad 0.94 \pm 0.01 *$ \\
\hline
\end{tabular}

${ }^{*} p<0.05$ vs controls with FPG $<5$ mmol/l; C = Caucasian, MA = Mexican American; FHD = family history of diabetes; BMI = body mass index; WHR = waist-to-hip ratio 


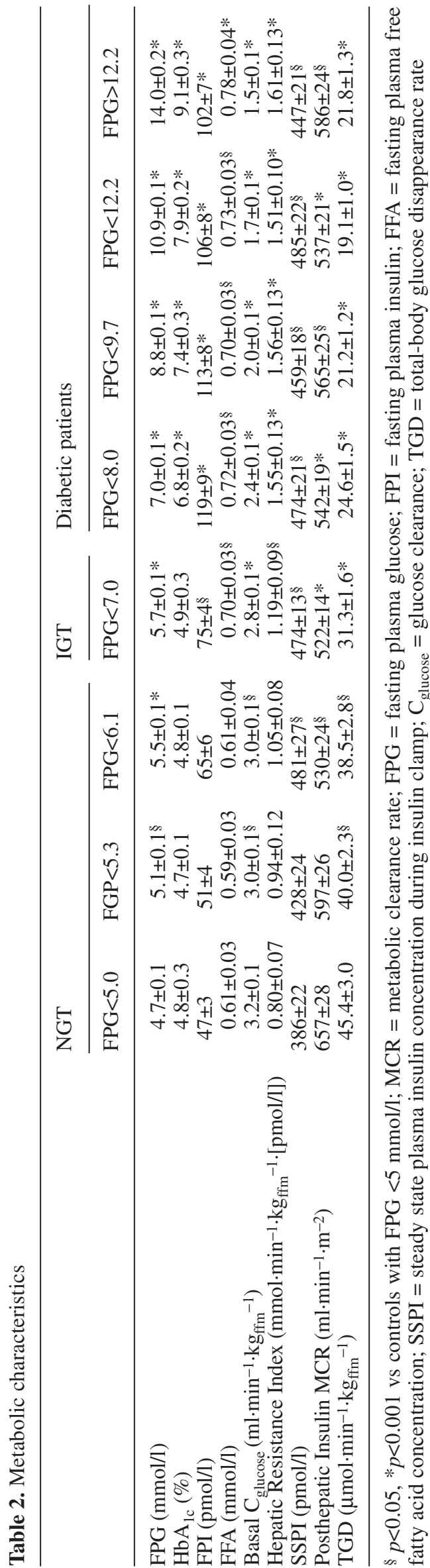

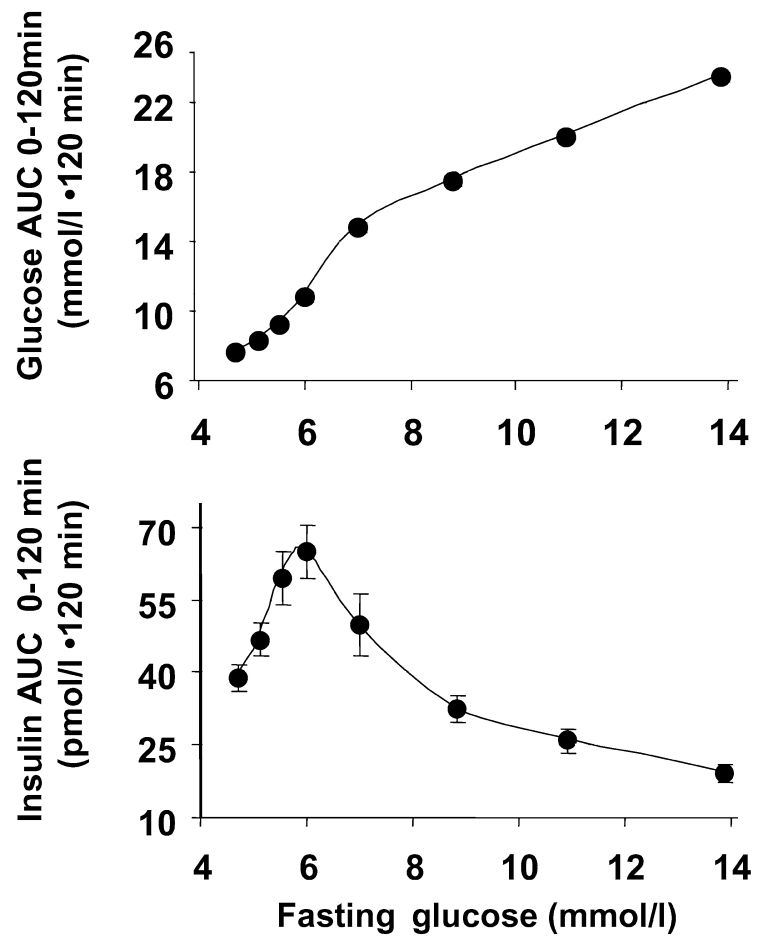

Fig. 1. Relationship between the fasting plasma glucose concentration (FPG) and the glucose (0-120 min) and insulin (0-120 min) AUC during the OGTT in subjects with normal glucose tolerance (NGT, divided into tertiles), impaired glucose tolerance (IGT), and Type 2 diabetes mellitus (T2DM, divided into quartiles)

U-shaped curve that has been referred to as Starling's curve of the pancreas (Fig. 1). In NGT and IGT, the 0 - to 120-min insulin AUC increased progressively with FPG; thereafter, there was a progressive decrease in T2DM subjects. The 0- to 30-min insulin AUC peaked in NGT subjects with a FPG less than $5.6 \mathrm{mmol} / \mathrm{l}$ and declined progressively in IGT and T2DM subjects. Thus, the defect in early insulin response manifests itself at an FPG that was lower than the defect in total ( 0 to $120 \mathrm{~min}$ ) insulin response. The fasting plasma insulin concentration rose progressively with the increase in fasting plasma glucose concentration $(\mathrm{r}=0.32, p<0.001)$ (Fig. 1) and severity of insulin resistance $(\mathrm{r}=0.51, p<0.001)$ (Table 2$)$.

Insulin response and 2-h plasma glucose. We then examined the plasma insulin response in relation to the 2-h PG during the OGTT. Since the beta cell responds to an increment in plasma glucose concentration with an increment in plasma insulin response [27], we calculated the incremental insulin response for both total (0 to $120 \mathrm{~min}$ ) and early (0 to $30 \mathrm{~min}$ ) secretory phases, as well as the incremental insulin response to the increment in plasma glucose concentration $(\Delta \mathrm{I} / \Delta \mathrm{G})$. As obesity is an insulin-resistant state and obese non-diabetic subjects secrete more insulin than lean individuals with a comparable level of glucose tolerance, we analysed beta-cell function separately in lean and 

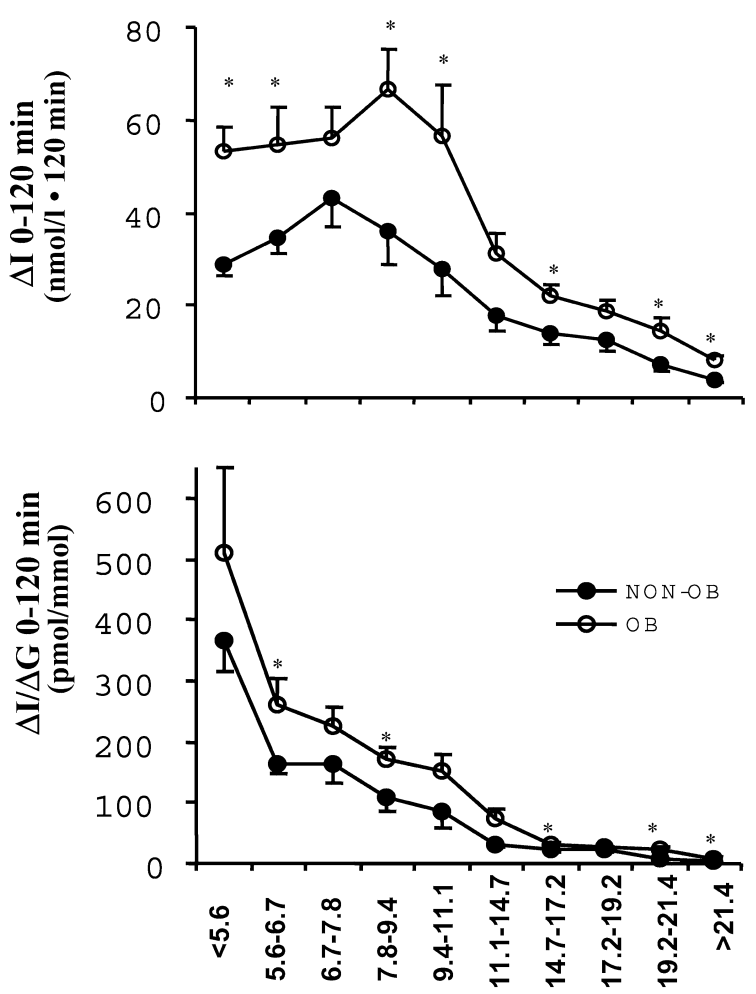

\section{2-hour Plasma glucose ( $\mathrm{mmol} / \mathrm{l})$}

Fig. 2. Relationship between the 2-h plasma glucose (2-h PG) concentration and the incremental insulin response (top) and the incremental insulin $(\Delta \mathrm{I})$ response factored by the incremental glucose $(\Delta \mathrm{G})$ response (bottom) during the $0-120 \mathrm{~min}$ period in lean and obese subjects. ${ }^{*} p<0.05$, obese vs non-obese

obese subjects (Fig. 2, upper panel). In both lean and obese subjects the typical inverted U-shaped curve was still observed between the incremental total insulin response and 2-h PG, a decline being evident in IGT subjects with a 2-h PG greater than $8.9 \mathrm{mmol} / \mathrm{l}$. Both ( 0 to 120 and 0 to $30 \mathrm{~min}$ ) incremental insulin responses in obese NGT and obese IGT subjects were approximately twice as big as those in the corresponding lean NGT and IGT groups. However, in the T2DM groups the difference became progressively less.

When the incremental total insulin response was related to the corresponding incremental glucose response, a different picture emerged. The difference between lean and obese subjects, with NGT or IGT, was diminished. Lean NGT subjects with a 2-h PG less than $5.6 \mathrm{mmol} / \mathrm{l}$ had the highest $\Delta \mathrm{I} / \Delta \mathrm{G}$ values (Fig. 2, lower panel); thereafter, there was a progressive, curvilinear decline in both the total and early $\Delta \mathrm{I} / \Delta \mathrm{G}$.

We also examined the plasma insulin response in relation to the severity of insulin resistance $(\Delta \mathrm{I} / \Delta \mathrm{G} \div \mathrm{IR}$, where $\mathrm{IR}=1 /[\mathrm{TGD} / \mathrm{I}])$ (Fig. 3). Firstly, the difference in the 'adjusted' insulin response between NGT and IGT subjects was reduced. Secondly, lean NGT subjects with a 2-h PG greater than $5.6 \mathrm{mmol} / \mathrm{l}$ already had a reduced ability to secrete insulin. Finally, there was no difference between lean and obese
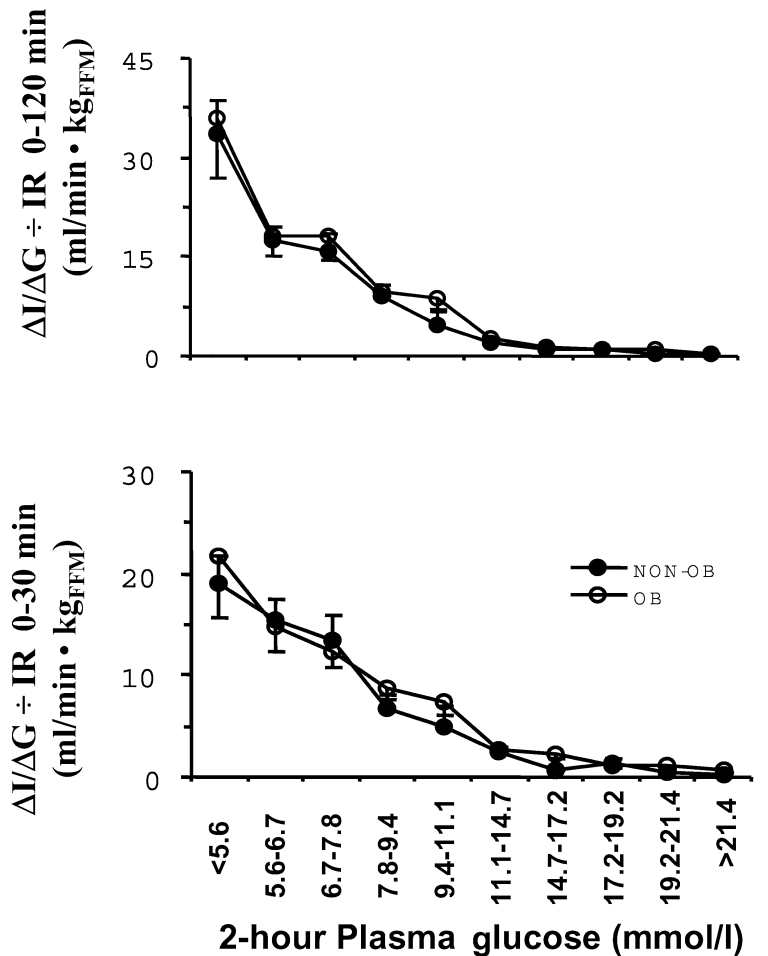

Fig. 3. Relationship between the $2-\mathrm{h}$ plasma glucose (2-h PG) concentration and the insulin secretion/insulin resistance index $(\Delta \mathrm{I} / \Delta \mathrm{G}$ factored by the severity of insulin resistance measured with the euglycemic insulin clamp) during the 0-120 min and 0-30 min time periods during the OGTT in lean and obese subjects
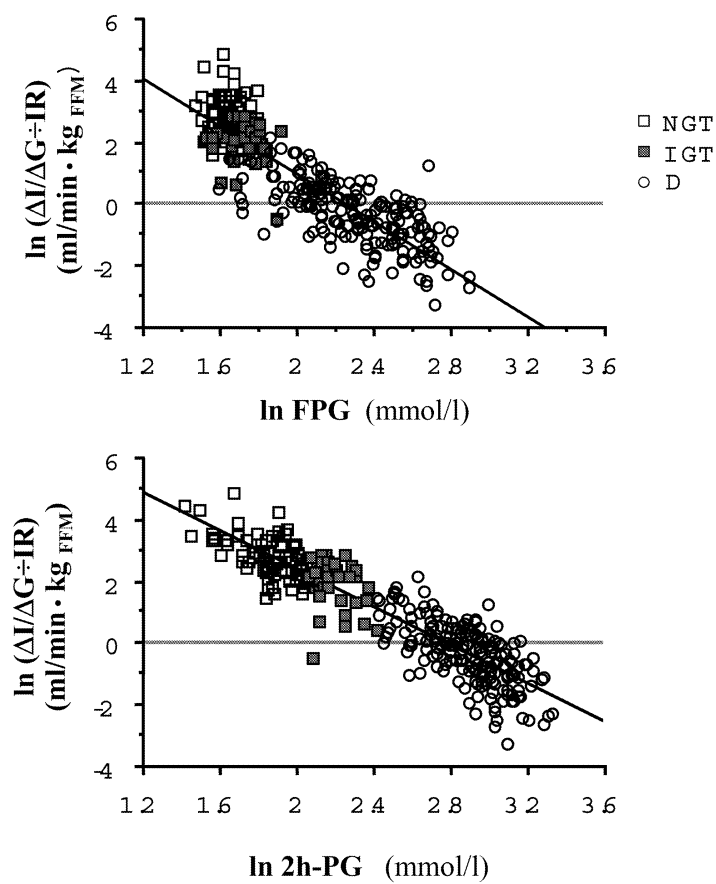

Fig. 4. Relationship between the insulin secretion/insulin resistance index $(\Delta \mathrm{I} / \Delta \mathrm{G}$ factored by the severity of insulin resistance measured with the euglycemic insulin clamp) and the fasting plasma glucose (FPG, top panel) and the 2-h plasma glucose (2-h PG, bottom panel) concentration (log-log scale) 
subjects with NGT, IGT, or T2DM (Fig. 3). When $\Delta \mathrm{I} / \Delta \mathrm{G} \div \mathrm{IR}$ is plotted against $\mathrm{FPG}$ or $2-\mathrm{h} \mathrm{PG}$ in a $\log -\log$ scale, a very strong linear inverse relationship $(\mathrm{r}=0.91, p<0.0001)$ is observed (Fig. 4). These results show that even within the NGT range there is a progressive decline in beta-cell function in both lean and obese subjects, and that this decline is closely related to the level of glucose tolerance.

The effect of ethnicity (Mexican American compared with Caucasian), family history of diabetes (one or more first-degree relatives), age and gender on $\Delta \mathrm{I} / \Delta \mathrm{G} \div \mathrm{IR}$ was examined by multivariate analysis, also including 2-h PG among the independent variables. Neither age nor sex, ethnicity or family history of diabetes were found to exert any influence on the insulin secretion/insulin resistance index $(p<0.0001)$.

\section{Discussion}

It generally is accepted that the emergence of T2DM is preceded by a stage of IGT $[1,2,3,6,7,8,9,10$, $11,12,14,16,17,18,19]$. T2DM ensues when the beta cell is not able to secrete sufficient amounts of insulin to offset the severity of insulin resistance. According to the criteria established by the American Diabetes Association [30], IGT is defined by a 2-h plasma glucose concentration between 7.8 and $11.1 \mathrm{mmol} / \mathrm{l}$ during an OGTT. Many studies have shown that IGT individuals are resistant to the action of insulin and that the progression from IGT to T2DM is associated with a decline in beta-cell function with little additional worsening of peripheral insulin resistance $[1,3$, $6,8,9,14,16,17,18,39]$. The defect in insulin secretion in IGT individuals is most evident when the early (0- to 30-min) plasma insulin response following glucose ingestion is examined. Typically, the total insulin area under the curve following oral or intravenous glucose is normal or increased $[1,2,3,8,10,17,18$, $23,24,25,26,40,41,42,43]$. Similarly, it is not uncommon to observe an increased or "normal" plasma insulin response in T2DM patients with mild fasting hyperglycaemia $(<7.8 \mathrm{mmol} / \mathrm{l})$, although the early (0- -30-min) insulin response is impaired [16, 44]. Our study systematically examined the plasma insulin response in relation to the 2-h plasma glucose concentration following oral glucose administration in individuals spanning a wide range of glucose tolerance, while simultaneously taking into account the major factors that influence beta-cell function, including the hyperglycaemic stimulus presented to the beta cell and the body's sensitivity to insulin. Moreover, it is unclear at what stage in the natural history of T2DM beta-cell function begins to deteriorate.

In this study, we have stratified NGT, IGT, and T2DM subjects on the basis of their 2-h PG, expressed the incremental insulin response per incremental glucose stimulus $(\Delta \mathrm{I} / \Delta \mathrm{G})$, and factored this by the pre- vailing level of insulin resistance (measured independently in each subject on a separate day with the euglycaemic insulin clamp). When beta-cell function is expressed in this manner, a very distinct pattern of insulin secretion emerges. The typical inverted Ushaped or Starling's curve of the pancreas [14] is no longer evident. Instead, there is a progressive decline in insulin secretion, even in individuals whose glucose tolerance is considered to be well within the normal range. Thus, NGT individuals with a $2-\mathrm{h}$ PG between 6.1 and $7.8 \mathrm{mmol} / \mathrm{l}$ already have a greater than $50 \%$ decline in the plasma insulin response to a glucose challenge, while IGT subjects with a 2-h PG between 7.8 and $11.1 \mathrm{mmol} / \mathrm{l}$ manifest a severely impaired plasma insulin response. This pattern of beta-cell dysfunction is observed whether one examines the early $(0-30 \mathrm{~min})$ or total $(0-120 \mathrm{~min})$ plasma insulin response following oral glucose. These results suggest that the onset of beta-cell dysfunction begins early in the natural history of T2DM, starting even before the onset of IGT, as defined by current diagnostic criteria [30]. It should be noted that the diagnostic criteria for IGT are somewhat arbitrary and are not based on any clinical or pathophysiologic abnormalities. Rather, they are based on the empiric observation that individuals with a 2 -h PG between 7.8 and $11.0 \mathrm{mmol} / \mathrm{l}$ have an increased risk of developing T2DM later in life compared to individuals with a 2-h PG less than $7.8 \mathrm{mmol} / \mathrm{l}$ [24]. Insulin resistance has been shown to be present in the first-degree relatives of T2DM individuals before the onset of IGT $[1,10,11,12,13,45$, $46,47,48]$ at a time when glucose tolerance is normal. This observation, taken in concert with the present findings concerning beta-cell dysfunction in individuals with NGT, underscores the arbitrariness of current IGT criteria, since the two major pathophysiological disturbances-insulin resistance and beta-cell dysfunction - are already well established in individuals with "normal" glucose tolerance.

Previous studies have used the frequently sampled intravenous glucose tolerance test to examine the dynamic interaction between insulin secretion and insulin sensitivity. These studies have shown that firstphase insulin secretion is inversely related to insulin sensitivity in a hyperbolic manner [17, 18]. It should be noted that the insulin secretion/insulin resistance index $(\Delta \mathrm{I} / \Delta \mathrm{G} \div \mathrm{IR})$ is equivalent to the so-called "disposition index". We named it the insulin secretion/ insulin resistance index since it describes the dynamic interaction between insulin secretion and insulin resistance, while "disposition" literally means "utilization" of glucose. Thus, the index describes the normal beta-cell response: if the degree of glucose tolerance does not change, the product of insulin secretion and tissue insulin sensitivity (referred to as the "disposition" index) remains constant and the subject moves up and down on the same hyperbolic curve $[17,18]$. Although the concepts underlying the FSIV- 
GTT are fundamentally sound, the technique has a number of drawbacks. Firstly, insulin secretion and insulin sensitivity are measured simultaneously in the same subject. As the plasma insulin response determines, in part, the fractional rate of glucose removal, the close inverse relationship between these two variables is somewhat predictable. The interpretive problems with simultaneous measurement of insulin secretion and insulin sensitivity during a single study, when both the plasma glucose and insulin concentrations are changing simultaneously, have been discussed previously [33, 49]. Secondly, the FSIVGTT only examines first-phase insulin secretion and in response to an unphysiological elevation in the plasma glucose concentration [50]. Moreover, the early insulin response is not related to the incremental glucose response, which can differ from subject to subject and which is a major determinant of the magnitude of insulin secretion [27]. Thirdly, the intravenous route of glucose administration differs from the normal route of glucose entry into the body via the gastrointestinal tract and does not, therefore, take into account the effect of incretin-potentiating factors on insulin secretion $[28,29,51]$.

The factors responsible for the progressive decline in beta-cell function in NGT individuals with a 2-h $\mathrm{PG}$ greater than $5.6 \mathrm{mmol} / \mathrm{l}$ remain to be determined. Although the fasting plasma FFA concentrations were higher in IGT and T2DM individuals compared to NGT subjects, we failed to find any correlation between the insulin secretion/insulin resistance index and the fasting plasma FFA concentration. In contrast, the 2-h PG(r=0.91, $p<0.0001)$, the mean plasma glucose during the OGTT $(\mathrm{r}=0.91, p<0.0001)$, FPG $(\mathrm{r}=0.86, p<0.0001)$, and the $\mathrm{HbA}_{1 \mathrm{c}}(\mathrm{r}=0.70, p<0.0001)$ all were strongly and inversely related to the insulin secretion/insulin resistance index in log-log plot. These results are consistent with the concept of "glucose toxicity", which states that small, chronic increases in the plasma glucose concentration inhibit insulin secretion $[52,53]$. It has been shown in partially pancreatectomised rats [53] that addition of sucrose to the drinking water to increase the mean fed plasma glucose concentration by as little as $0.9 \mathrm{mmol} / \mathrm{l}$ caused a marked deterioration in insulin secretion when the islets were presented with a glucose challenge in vitro. Consistent with this hypothesis, treatment of hyperglycaemia with phlorizin, an inhibitor of renal glucose transport, normalises insulin secretion in partially pancreatectomised diabetic rats [54]. Conversely, one could argue that some intrinsic (i.e., genetic) or extrinsic (i.e., incretin deficiency) factor is responsible for the biological variation in beta-cell function in NGT individuals.

The present results also help to clarify the function of the beta cell in obese individuals. Irrespective of the degree of glucose tolerance, when the insulin secretory response is compared to the concomitant severity of insulin resistance, it can be seen that for any given glucose stimulus the beta-cell response in obese individuals is superimposable on that of lean subjects. Thus, throughout the range of glucose tolerance ranging from NGT to IGT to T2DM, the beta cells of obese individuals function in an identical fashion to those of lean subjects.

In summary, beta-cell function has been evaluated with the insulin secretion/insulin resistance index in individuals spanning a wide range of oral glucose tolerance. When the incremental plasma insulin response is related to the glucose stimulus and the severity of insulin resistance, a progressive decline in beta-cell response is observed in NGT individuals with a 2-h PGgreater than $5.6 \mathrm{mmol} / \mathrm{l}$ during a $75-\mathrm{g}$ OGTT. When insulin secretion is related to the underlying insulin resistance, beta-cell function in obese individuals with NGT, IGT, and T2DM is superimposable on that of lean individuals with the same category of glucose tolerance.

Acknowledgements. The authors wish to thank our nurses (M. Ortiz, D. Frantz, S. Mejorado, J. Shapiro, J. Kincaid, J. King, N. Diaz, P. Wolf) for their assistance in carrying out the insulin clamp and OGTT studies. This work was supported by NIH grant DK24092, NIH GCRC grant MOI-RR-01346, a VA merit Award, funds from the VA Research Foundation, an EFSDNovo Nordisk Type 2 Programme Focused Research Grant, and funds from the Italian Ministry of University and Scientific Research (MURST).

\section{References}

1. DeFronzo RA (1997) Pathogenesis of type 2 diabetes: metabolic and molecular implications for identifying diabetes genes. Diabetes Rev 4:177-269

2. Polonsky KS, Sturis J, Bell G (1996) Non-insulin-dependent diabetes mellitus: a genetically programmed failure of the beta cell to compensate for insulin resistance. N Engl J Med 334:777-783

3. Weyer C, Bogardus C, Mott DM et al. (1999) The natural history of insulin secretory dysfunction and insulin resistance in the pathogenesis of type 2 diabetes mellitus. J Clin Invest 104:787-94

4. Haffner SM, Stern MP, Mitchell BD et al. (1990) Incidence of type II diabetes in Mexican Americans predicted by fasting insulin and glucose levels, obesity, and body-fat distribution. Diabetes 39:283-288

5. Haffner SM, Miettinen H, Gaskill SP et al. (1995) Decreased insulin secretion and increased insulin resistance are independently related to the 7-year risk of NIDDM in Mexican Americans. Diabetes 44:1386-1391

6. Lillioja S, Mott DM, Howard BV et al. (1988) Impaired glucose tolerance as a disorder of insulin action: longitudinal and cross-sectional studies in Pima Indians. N Engl J Med 318:1217-1225

7. Dowse GK, Zimmet PZ, Collins VR (1996) Insulin levels and the natural history of glucose intolerance in Nauruans. Diabetes 45:1367-1372

8. Saad MF, Knowler WC, Pettitt D et al. (1989) Sequential changes in serum insulin concentration during development of non-insulin dependent diabetes. Lancet 1:1356-1359 
9. Hansen BC, Bodkin NH (1986) Heterogeneity of insulin responses: phases leading to type 2 (non-insulin-dependent) diabetes mellitus in the rhesus monkey. Diabetologia 29:713-719

10. Eriksson J, Franssila-Kallunki A, Ekstrand A et al. (1989) Early metabolic defects in persons at increased risk for non-insulin-dependent diabetes mellitus. N Engl J Med 321:337-343

11. Martin BC, Warram JH, Krolewski AS et al. (1992) Role of glucose and insulin resistance in development of type 2 diabetes mellitus: results of a 25-year follow-up study. Lancet 340:925-929

12. Lillioja S, Nyomba BL, Saad MF et al. (1991) Exaggerated early insulin release and insulin resistance in a diabetesprone population: a metabolic comparison of Pima Indians and Caucasians. J Clin Endocrinol Metab 73:866-876

13. Gulli G, Ferrannini E, Stern M et al. (1992). The metabolic profile of NIDDM is fully established in glucose-tolerant offspring of two Mexican-American NIDDM parents. Diabetes 41:1575-1586

14. DeFronzo RA (1988) Lilly Lecture. The triumvirate: beta cell, muscle, liver. A collusion responsible for NIDDM. Diabetes 37:667-687

15. Diamond MP, Thornton K, Connolly-Diamond M et al. (1995) Reciprocal variation in insulin-stimulated glucose uptake and pancreatic insulin secretion in women with normal glucose tolerance. J Soc Gynecol Invest 2:708715

16. Reaven GM, Hollenbeck CB, Chen YDI (1989) Relationship between glucose tolerance, insulin secretion, and insulin action in non-obese individuals with varying degrees of glucose tolerance. Diabetologia 32:52-55

17. Kahn SE (2001) Clinical review 135. The importance of beta-cell failure in the development and progression of type 2 diabetes. J Clin Endocrinol Metab 86:404758

18. Bergman RN, Finegood DT, Kahn SE (2002) The evaluation of $\beta$-cell dysfunction and insulin resistance in type 2 diabetes. Europ J Clin Invest 32[Suppl 3]:35-45

19. Saad MF, Knowler WC, Petitt DJ et al. (1988) The natural history of impaired glucose tolerance in the Pima Indians. N Engl J Med 319:1500-1505

20. Hollenbeck CB, Reaven GM (1987) Variations in insulinstimulated glucose uptake in healthy individuals with normal glucose tolerance. J Clin Endocrinol Metab 64:11691173

21. Reaven GM (1988) Banting Lecture: Role of insulin resistance in human disease. Diabetes 37:595-607

22. Ferrannini E, Natali A, Bell P et al. (1997) Insulin resistance and hypersecretion in obesity. J Clin Invest 100:1166-1173

23. Efendic S, Grill V, Luft R et al. (1988) Low insulin response: a marker of pre-diabetes. Adv Exp Med Biol 246:167-174

24. Pimenta W, Korytkowski M, Mitrakou A et al. (1995) Pancreatic beta-cell dysfunction as the primary genetic lesion in NIDDM: evidence from studies in normal glucose-tolerance individuals with a first degree NIDDM relative. JAMA 273:1855-1861

25. Larsson H, Ahren B (1996) Failure to adequately adapt to reduced insulin sensitivity with increased insulin secretion in women with impaired glucose tolerance. Diabetologia 39:1099-1107

26. Beck Nielsen H, Groop LC (1994) Metabolic and genetic characteristics of prediabetic states: sequence of events leading to non-insulin-dependent diabetes mellitus. J Clin Invest 94:1714-1721
27. Ahren B, Taborsky GJ (2003) Beta-cell function and insulin secretion. In: Porte D, Sherwin RS, Baron A (eds) Ellenberg Rifkins diabetes mellitus. McGraw Hill, New York, pp 43-65

28. Fehmann HC, Goke R, Goke B (1995) Cell and molecular biology of the incretin hormones glucagons-like peptide-I and glucose-dependent insulin releasing polypeptide. Endocr Rev 16:390-410

29. Drucker DJ (1998) Glucagon-like peptides. Diabetes. 47:159-69

30. The Expert Committee on the Diagnosis and Classification of Diabetes Mellitus (1997) Report of the Expert Committee on the Diagnosis and Classification of Diabetes Mellitus. Diabetes Care 20:1183-1197

31. Frankenfield DC, Rowe WA, Cooney RN et al. (2001) Limits of body mass index to detect obesity and predict body composition. Nutrition 17:26-30

32. Bonora E, Del Prato S, Bonadonna RC et al. (1992) Total body fat content and fat topography are associated differently with in vivo glucose metabolism in nonobese and obese nondiabetic women. Diabetes 41:1151-1159

33. DeFronzo RA, Tobin JD, Andres R. (1979) The glucose clamp technique. A method for quantifying insulin secretion and resistance. Am J Physiol 6:E214-E223

34. Groop LC, Bonadonna RC, Del Prato S et al. (1989) Effect of insulin on oxidative and non-oxidative pathways of glucose and FFA metabolism in NIDDM. Evidence for multiple sites of insulin resistance. J Clin Invest 84:205-213

35. Steele RW, Wall JS, DeBodo RC et al. (1956) Measurement of size and turnover rate of body glucose pool by the isotope dilution method. Am J Physiol 187:15-24

36. DeFronzo RA, Ferrannini E, Simonson DC (1989) Fasting hyperglycemia in non-insulin dependent diabetes mellitus: contributions of excessive hepatic glucose production and impaired tissue glucose uptake. Metabolism 38:387-395

37. DeFronzo RA, Sherwin RS, Hendler R et al. (1978) Insulin binding to monocytes and insulin action in human obesity, starvation, and refeeding. J Clin Invest 62:204-213

38. Perley MJ, Kipnis DM (1967) Plasma insulin responses to oral and intravenous glucose: studies in normal and diabetic sujbjects. J Clin Invest 46:1954-62

39. Buchanan TA, Xiang AH, Peters RK et al. (2002) Preservation of pancreatic beta-cell function and prevention of type 2 diabetes by pharmacological treatment of insulin resistance in high-risk hispanic women. Diabetes 51:2796-803

40. Mitrakou A, Kelley D, Mokan M et al. (1992) Role of reduced suppression of glucose production and diminished, early insulin release in impaired glucose tolerance. N Engl J Med 326:22-29

41. Chen K-W, Boyko EJ, Bergstrom RW et al. (1995) Earlier appearance of impaired insulin secretion than of visceral adiposity in the pathogenesis of NIDDM. 5-year follow up of initially non-diabetic Japanese-American men. Diabetes Care 18:747-753

42. Ahren B, Pacini G (1997) Impaired adaptation of firstphase insulin secretion in postmenopausal women with glucose intolerance. Am J Physiol 273:E701-E710

43. Cook JT, Page RC, Levy JC et al. (1993) Hyperglycaemic progression in subjects with impaired glucose tolerance: association with decline in beta cell function. Diabet Med 10:321-326

44. Yalow RS, Benson SA (1960) Immonoassay of endogenous plasma insulin in man. J Clin Invest 39:1157-175

45. Haffner SM, Miettinen H, Stern MP. (1996) Insulin secretion and resistance in nondiabetic Mexican Americans and non-Hispanic whites with a parental history of diabetes. J Clin Endocrinol Metab 81:1846-1851 
46. Lillioja S, Mott DM, Zawadzki JK et al. (1987) In vivo insulin action is familial characteristic in non-diabetic Pima Indians. Diabetes 36:1329-1335

47. Vaag A, Henriksen JE, Madsbad S et al. (1995) Insulin secretion, insulin action, and hepatic glucose production in identical twins discordant for non-insulin-dependent diabetes mellitus. J Clin Invest 95:690-698

48. Gelding S, NithyananthanR, Chan S et al. (1994) Insulin sensitivity in non-diabetic relatives of patients with noninsulin-dependent diabetes from two ethnic groups. Clin Endocrinol 40:55-62

49. Caumo A, Vicini P, Zachwieja JJ et al. (1999) Undermodeling affects minimal model indexes: insights from a two-compartment model. Am J Physiol 276:E1171E1193
50. Bergman RN, Phillips LS, Cobelli C (1981) Physiologic evaluation of factors controlling glucose tolerance in man, measurement of insulin sensitivity and $\beta$-cell glucose sensitivity from the response to intravenous glucose. J Clin Invest 68:1456-1467

51. Kieffer TJ, Habener JF (1999) The glucagon-like peptides. Endocr Rev 20:876-913

52. Rossetti L, Giaccari A, DeFronzo RA (1990) Glucose toxicity. Diabetes Care-Rev 13:610-630

53. Leahy JL, Cooper HE, Werr GC (1987) Impaired insulin secretion associated with near normoglycemia. Diabetes 36:459-464

54. Rossetti L, Shulman GI, Zawalich W et al. (1987) Effect of chronic hyperglycemia on in vivo insulin secretion in partially pancreatectomized rats. J Clin Invest 80:1037-1044 